\title{
EL SECRETO DE VERA DRAKE Y 4 MESES, 3 SEMANAS, 2 DÍAS: EL ABORTO EN EL RETRATO DE UNA ÉPOGA
}

\author{
María Abad Colom \\ Universidad de Alicante \\ maria.abad@ua.es
}

Black and white is never really black and white. It's shades of grey

Martin Scorsese

\section{RESUMEN}

El director y guionista británico Mike Leigh es conocido por su cine de temática social, en el que retrata la vida cotidiana de familias británicas comunes y expone situaciones y sentimientos con los que el espectador se siente fácilmente identificado. El Secreto de Vera Drake fue sin duda uno de sus grandes éxitos, especialmente entre la crítica, recibiendo numerosos premios internacionales. Por otra parte, el cruel régimen comunista, la libertad y la resistencia a la dictadura son los grandes temas del cine rumano de nuestros días, un cine que aborda la realidad desde una perspectiva sarcástica y llena de humor negro. Representante de esta nueva ola, Cristian Mungiu y su extraordinaria 4 meses, 3 semanas, 2 días llevaron el cine rumano a los puestos de honor del cine europeo.

Palabras clave: Aborto, dictadura, políticas natalistas, Cristian Mungiu, Mike Leigh.

\section{INTRODUCCIÓN}

Dice el maestro Scorsese que el blanco y el negro no son en realidad blanco y negro, sino tonos de gris. No solo tiene toda la razón, sino que los españoles ya lo sabíamos, y lo plasmamos en nuestro refranero popular mucho antes de que él hubiera siquiera nacido: allá por la mitad del siglo XIX, cuando se popularizó una composición del poeta madrileño Ramón Campoamor que decía "[...] y es que en el mundo traidor nada hay verdad ni mentira; todo es según el color del cristal con que se mira».

Ser consciente de que la vida está hecha de pequeños matices, de infinitos tonos de gris, es fundamental para mantener una mente abierta. En este sentido, las películas que nos 
ocupan son, precisamente, dos vidrieras de colores que van cambiando a medida que la luz incide sobre ellas o, lo que es lo mismo, según quiera el espectador entenderlas y según el director o el guionista prefigure la descodificación o interpretación del mensaje.

Una de las capacidades más admirables y extraordinarias del cine es la de contarnos historias que nos hagan pensar y que retraten unas circunstancias, un momento y un lugar sin emitir juicios de valor, al menos no de manera patente, dejando que seamos nosotros quienes saquemos nuestras propias conclusiones. Crear una película que permita al espectador adentrarse en un tema y reflexionar sobre él a partir de lo que ve no es tarea fácil, pero El secreto de Vera Drake (Vera Drake, Mike Leigh, 2004) y 4 meses, 3 semanas, 2 días (4 luni, 3 săptămâni şi 2 zile, Cristian Mungiu, 2007) cumplen con creces este objetivo, convirtiéndose por ello en cintas imprescindibles para los devotos del cine interpelante. Películas como estas plantean cuestiones morales y se posicionan en el polo opuesto al cine comercial americano más simplista y de visión maniquea sobre la vida y el comportamiento humano.

\section{LAS PELÍCULAS OBJETO DE REFLEXIÓN}

El director y guionista británico Mike Leigh es precisamente conocido por su cine de temática social, en el que retrata la vida cotidiana de familias británicas comunes y expone situaciones y sentimientos con los que el espectador se siente fácilmente identificado. El secreto de Vera Drake fue sin duda uno de sus grandes éxitos, especialmente entre la crítica, recibiendo numerosos premios internacionales. Su fantástica actriz protagonista, Imelda Staunton, llegó a estar nominada al Oscar en 2005 por su trabajo en esta película, aunque el premio acabó recayendo en Hilary Swank por Million Dollar Baby.

En cuanto a Mungiu, su extraordinaria 4 meses, 3 semanas, 2 días se enmarca dentro de la llamada nueva ola rumana, que comenzó en torno al año 2004 y ha encumbrado merecidamente al cine de este país a los puestos de honor del cine europeo. Se trata de películas generalmente intimistas, con gran vocación de convertirse en espejo de una realidad y una sociedad poco conocida fuera de las fronteras de Rumanía. Cristian Mungiu no es una excepción a este objetivo, y de hecho considera esta cinta como la primera de su trilogía sobre la sociedad rumana durante el régimen de Nicolae Ceauşescu, una etapa que el dictador bautizó como Epoca de $\mathrm{Aur}^{3}$ (La Edad de Oro). El cruel régimen comunista, la libertad y la resistencia a la dictadura son los grandes temas del cine rumano de nuestros días. No obstante, la mayoría de estas películas aborda tan espinosa realidad desde una perspectiva sarcástica y llena de humor negro. La nueva ola rumana pone un refrescante contrapunto al modelo comercial hollywoodiense y resulta imprescindible para todo aquel que disfrute del buen cine.

Estas películas son, indudablemente, dos excelentes ejemplos de la buena salud del cine europeo de las últimas décadas. A primera vista, se podría pensar que tanto El secreto de Vera Drake como 4 meses, 3 semanas, 2 días hablan únicamente sobre el aborto (clandestino en ambos casos), pero es innegable que son muchísimo más que eso. El aborto es el elemento vertebrador de las películas, pero ni mucho menos el tema único. Como se mencionaba con

3 En 2009 se publicó una colección de cinco historias cortas sobre el final del período comunista en Rumanía llamada Amintiri din Epoca de Aur (Historias de la Edad de Oro, en su versión en castellano), cuyo guión firmaba también Cristian Mungiu. No obstante, estas historias no pertenecen ni tienen relación con la mencionada trilogía, que el director inició con 4 meses, 3 semanas, 2 días y todavía no ha concluido. 


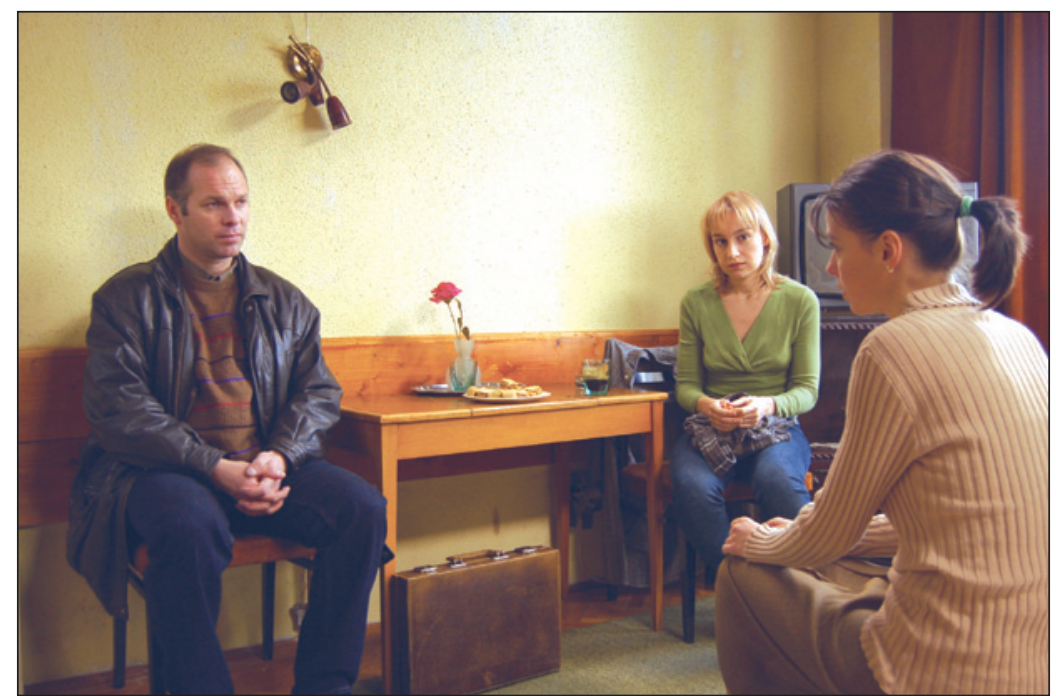

4 luni, 3 săptămâni şi 2 zile (4 meses, 3 semanas, 2 días, Cristian Mungiu, 2007)

anterioridad, la capacidad de sus directores para abordar un tema tan complejo como este desde una perspectiva abiertamente descriptiva, sin caer en lecciones morales ni juicios de valor, las convierte en películas excepcionales. A su particular modo, cada una de ellas retrata una época y un lugar a través de dos sólidas y muy creíbles protagonistas femeninas que, a pesar de ser enteramente diferentes, tienen también mucho en común. Tanto Leigh como Mungiu logran con maestría presentar un tema lleno de aristas y contrastes en el que el espectador se involucra, haciéndolo suyo, sin propiciar un posicionamiento hacia uno u otro lado. Esta característica aporta al espectador la sensación de que es libre de interpretarlas como considere. Las dos cintas dibujan la realidad de sus protagonistas de la manera más aséptica posible, pero al mismo tiempo resultan tremendamente realistas y detallistas, consiguiendo así que el espectador se meta en la piel de los personajes, entienda sus motivaciones y, en definitiva, los sienta como propios. Nosotros somos Vera, somos Otilia, y sufrimos y vivimos con ellas cada etapa de su complejo camino, inmersos en esa realidad cruda y fría.

\section{CONTEXTO SOCIAL Y DILEMA MORAL}

Esa realidad es, en el caso de El secreto de Vera Drake, la Inglaterra gris, triste y pobre de la posguerra, en el año 1950. Para el espectador español, se trata probablemente de un contexto bastante más conocido y familiar que el expuesto en 4 meses, 3 semanas, 2 días. En la cinta de Mike Leigh se nos presenta a una pequeña familia que vive en un barrio de clase obrera, sin lujos ni comodidades, y que está encabezada por una madre trabajadora y afable que es, además, un ejemplo de generosidad humana. Vera Drake no deja nunca de ayudar a sus vecinos, invita a cenar a quien ve muy solo, cuida de su madre enferma, trata a sus hijos con afecto y quiere a su marido. Es, sin lugar a dudas, la capitana de un barco que de no ser por ella se hundiría sin remedio en la miseria y la depresión, como ocurre de hecho en el caso de sus vecinos. Vera es feliz con su sencilla vida y dedica mucho tiempo a tratar de mejorar la de los demás. Para ella esto incluye ayudar a jóvenes sin recursos que han cometido un desliz o que, a consecuencia de una violación, se encuentran con un embarazo no deseado. Vera no se cuestiona la moralidad o inmoralidad del aborto porque para ella lo importante es ayudar a esas jóvenes que no tienen a quién acudir. Hasta que no es detenida y juzgada 
por culpa de un instrumental sin desinfectar, Vera no se enfrenta a la realidad: el aborto es ilegal y está penado por la ley. A pesar del calvario que su detención y procesamiento le suponen, probablemente lo más dramático e intenso de la película sea contemplar cómo esa familia anteriormente feliz y sin preocupaciones empieza a desmoronarse en cuanto su figura principal se tambalea. Vera no solo se enfrenta al juicio de la ley, se enfrenta también al de su propia familia.

El contexto en el que transcurre la acción de 4 meses, 3 semanas, 2 días es completamente diferente y, al mismo tiempo, tiene muchos puntos en común con El secreto de Vera Drake. En esta ocasión, nos trasladamos a la poco conocida Rumanía de 1987, en plena dictadura comunista de Nicolae Ceauşescu y su esposa (y viceprimera ministra) Elena. El matrimonio Ceauşescu dominó Rumanía con mano de hierro durante veinticuatro años, en los cuales los ciudadanos se vieron sometidos a innumerables privaciones mientras la pareja presidencial y la nomenclatura vivían en la opulencia. Además, el culto a la personalidad de los Ceauşescu impuesto durante los años de la dictadura fue un fenómeno sin precedentes: el rostro de ambos estaba presente a lo largo y ancho de todo el país, y la megalomanía del dictador llevó a la construcción en el centro de Bucarest de un inmenso palacio presidencial llamado paradójicamente la casa del pueblo, en el que se invirtieron millones de lei mientras la población sufría escasez y restricciones de todo tipo.

En este contexto, y a pesar de que Nicolae Ceauşescu fuera la cabeza visible del régimen, era de sobra conocido el enorme poder de su esposa, cuyo nivel de estudios (elemental) le valió para ser miembro de la Academia Rumana de la Ciencia y autora de abundantes publicaciones científicas. Según muchas fuentes, fue precisamente Elena Ceauşescu quien impuso una fiera persecución y penalización del aborto, propiciando la creación de la llamada Ley de Continuidad Nacional, según la cual los embriones eran propiedad del estado rumano y cada familia estaba obligada a tener al menos cuatro hijos. Como es de imaginar, los anticonceptivos estaban completamente prohibidos, y el aborto era una actividad ilegal que llevaba a la cárcel a quien practicaba la intervención, a quien la recibía y a cualquier intermediario, si lo hubiera. Como se ve en la película, el régimen de Ceauşescu estaba también caracterizado por dos elementos centrales: por un lado, el control estricto de las actividades de los ciudadanos (¿cuántas veces les piden a los protagonistas el buletin, es decir, el carnet de identidad?), que unas veces se llevaba a cabo por pura rutina, mientras que otras era una forma más de ejercer la represión; por otro lado, la presencia de la policía secreta, la Securitate, que se encargaba de aplastar cualquier signo de oposición mediante un férreo control sobre la libertad de expresión y los medios de comunicación. Durante la dictadura, las denuncias a la Securitate por parte de los propios conciudadanos y vecinos no eran infrecuentes, por lo que todos, incluidas Otilia y Găbiţa, se esforzaban al máximo por guardar las apariencias para evitar ser denunciados como enemigos del régimen. A pesar de no ser ni tan siquiera nombrada en la cinta, la huella de la macabra Securitate impregna cada movimiento y decisión de sus protagonistas.

Desde el punto de vista descriptivo, esta película consigue trasladarnos visualmente al Bucarest de finales del comunismo, apenas dos años antes de la caída del régimen. Estos años constituyen uno de los períodos más sombríos de la historia de Rumanía, caracterizados por la represión más absoluta, la desconfianza de todo y de todos, la falta de lo más básico y la tiranía cada vez más despiadada del aparato político. A pesar de que en 1987 ya se daban signos de la inminente sublevación del pueblo que desembocaría en la Revolución Rumana 
de 1989, la mano ejecutora del régimen seguía siendo inexorable. La película respira tristeza, pobreza, represión y desesperación y, al mismo tiempo, nos muestra a unas protagonistas completamente resignadas al tiempo y las circunstancias que les ha tocado vivir. Otilia y Găbiţa no se rebelan ni se quejan, sino que se enfrentan a su realidad con resignación, cosa que hace, si cabe, aún más opresiva la atmósfera del Bucarest donde se desarrolla la acción. Aunque lo intenten, las protagonistas huyen de una situación asfixiante para acabar inmersas en otra más angustiosa aún.

El aborto clandestino no pretende ser el tema central de estas dos películas, pero está, evidentemente, presente en todo momento, y es el elemento a partir del cual se toma el pulso a la realidad de ambos tiempos y lugares. En El secreto de Vera Drake, el aborto es reflejo de las diferencias de clase: mientras que las jóvenes ricas pueden abortar de forma legal, abierta y segura, las pobres se ven obligadas a arriesgar sus vidas en procedimientos ilegales e insalubres. Lo mismo ocurre en 4 meses, 3 semanas, 2 días, donde la prohibición de abortar y el deber de parir son una forma más de controlar al pueblo y de asegurar su obediencia y dependencia, además de obtener mano de obra gratuita: durante el régimen, grandes obras públicas y campañas agrícolas se llevaron a cabo con contingentes de jóvenes que cumplían el servicio militar obligatorio. Ni en la cinta de Leigh ni en la de Mungiu se nos presenta el aborto como una cuestión blanca o negra: los dos directores se limitan a mostrarnos la realidad a través de unos personajes cuyas decisiones (estemos de acuerdo con ellas o no) nos resultan humanas y comprensibles. Tanto es así, que llegamos a simpatizar no solo con la buena de Vera y sus nobles intenciones, con Otilia y su férreo sentido de la amistad y con Găbiţa y su negativa a aceptar la realidad, sino también, aunque nos duela y nos desgarre, con el señor Bebe, que se lucra practicando abortos ilegales y no tiene escrúpulos a la hora de exigir otro tipo de pagos cuando más desesperadas están las protagonistas. Incluso a un personaje así, a quien inicialmente podríamos describir como movido por la avaricia, despiadado y depravado, podemos llegar a entenderle.

\section{MUJER Y SOCIEDAD}

Ambos directores se sirven de un hecho tan dramático como el aborto para mostrar una cara de los personajes que hasta entonces permanecía oculta. En el caso de Vera es su propio hijo Sid quien la cuestiona, la desprecia y censura sus actos. Ella misma justifica sus decisiones desde un punto de vista que, aun siendo completamente legítimo, no deja de ser ingenuo y poco realista. En el de Otilia, es ella misma quien se descubre cruzando la línea de lo que una amiga haría por otra para que Găbiţa pueda abortar. Otilia asiste, además, al desmoronamiento del resto de su vida, ya que la situación de su amiga hace que se cuestione cómo serían las cosas si su novio la dejara embarazada. ¿La obligaría a abortar? ¿Se casarían? Ella no quiere casarse y convertirse en ama de casa con pretensiones de intelectual, pero ¿pasaría por lo mismo que deberá pasar su amiga? ¿Soportaría la visión del cuarto de baño sobre el que Mungiu detiene la cámara? Otilia acaba torturándose con todas estas preguntas a consecuencia de su decisión de apoyar y ayudar a su amiga durante el proceso, y el espectador no puede evitar preguntarse cuál sería su propia reacción y qué decisiones habría tomado él o ella de haber estado en su lugar.

En muchos sentidos, en ambas películas la mujer es la gran perjudicada por las circunstancias y las normas y, al mismo tiempo, el pilar sobre el que se sostiene el resto de relaciones humanas 
que se nos presenta. Vera ejerce de eje de su familia. A su manera, es una mujer fuerte que consigue llenar de positividad una vida claramente difícil y llena de penurias. Otilia, por su parte, es el gran apoyo de su amiga Găbiţa y quien hace posible que esta aborte, encargándose de absolutamente todo y soportando por ello una carga excesiva. Tanto Otilia como Vera se ven indefensas ante una realidad y una sociedad en la que las grandes decisiones están tomadas por los hombres, aunque atañan directamente a la salud y el bienestar de las mujeres.

Por otro lado, es interesante destacar cómo los directores utilizan el mercado negro como elemento que hace aún más evidente el ambiente hostil y de pura supervivencia que se respiraba en estas épocas. En la posguerra dura y pobre que vemos en El secreto de Vera Drake, el mercado negro es fuente tanto de pequeños caprichos -el azúcar, por ejemplo-, como de grandes remedios para grandes problemas (un aborto casero). Vera actúa tanto de cliente que adquiere pequeños lujos para su familia como de proveedora de abortos clandestinos. Del mismo modo, en la Rumanía comunista de 4 meses, 3 semanas, 2 días el mercado negro es la única manera de conseguir bienes preciados como café o tabaco, que en aquel momento resultaban a su vez imprescindibles para sobornar a cualquier persona de la que se necesitara algo. En esta ocasión, vemos cómo Otilia busca desesperadamente un paquete de cigarrillos Kent para completar los requisitos establecidos por el señor Bebe.

\section{REFLEXIÓN FINAL}

En definitiva, lo que hace especiales a ambas películas es que están llenas de esos tonos de gris en los que repara Scorsese, con lo que cada espectador puede aplicar sus propios filtros de color para reflexionar sobre un tiempo y unas circunstancias. Además del aborto, las historias de Vera y Otilia nos invitan a pensar sobre la amistad, la lealtad, la traición, la hipocresía de la sociedad, la solidez de la familia, la justicia y la delgada línea que separa la bondad de la ingenuidad.

\section{FUENTES CONSULTADAS}

«4 meses, 3 semanas, 2 días», Filmaffinity [en línea] Filmaffinity.com, 2002. [Consulta: 1 abril 2016], disponible en: http://www.filmaffinity.com/es/film178494.html.

«Academy Awards for 2005», The Internet Movie Database [en línea]. IMDb.com, 2009. [Consulta: 1 abril 2016]. Disponible en: http://www.imdb.com/event/ev0000003/2005.

CAMPOAMOR, Ramón, Doloras, humoradas y pequeños poemas. Palencia, Simancas Ediciones, 2003.

«El Secreto de Vera Drake (2004)», The Internet Movie Database [en línea]. IMDb.com, 2009. [Consulta: 1 abril 2016]. Disponible en: http://www.imdb.com/title/tt0383694/?ref_=fn_ al_tt_1.

«El Secreto de Vera Drake», Filmaffinity [en línea]. Filmaffinity.com, 2002. [Consulta: 1 abril 2016]. Disponible en: http://www.filmaffinity.com/es/film296191.html.

LEIGH, Mike (dir.), El secreto de Vera Drake [DVD], guion Mike Leigh, producida por Thin Man Films/Fine Line Features, Reino Unido, producida en 2004, duración 125 min. [2005].

MUNGIU, Cristian (dir.), 4 luni, 3 săptămâni şi 2 zile [DVD], guion Cristian Mungiu, coproducida entre Rumanía y Bélgica; Mobra Films Productions/Postproduction Abis Studio/Saga Films, Rumanía, producida en 2007, duración 113 min. [2011]. 